\title{
Oral administration of the amino acids cystine and theanine attenuates the adverse events of $S-1$ adjuvant chemotherapy in gastrointestinal cancer patients
}

\author{
Takashi Tsuchiya $^{1} \cdot$ Hiroshi Honda $^{1} \cdot$ Masaya Oikawa $^{1} \cdot$ Tetsuya Kakita $^{1} \cdot$ \\ Atsushi Oyama ${ }^{1} \cdot$ Hidekazu Oishi $^{1} \cdot$ Katsuyuki Tochikubo $^{2}$. Takanao Hashimoto ${ }^{2}$. \\ Shigekazu Kurihara $^{3} \cdot$ Tetsuro Shibakusa $^{3}$. Takashi Kayahara ${ }^{4}$
}

Received: 5 March 2016 / Accepted: 24 May 2016 / Published online: 15 June 2016

(C) The Author(s) 2016. This article is published with open access at Springerlink.com

\begin{abstract}
Background Nutritional therapy is used to reduce the adverse events (AEs) of anticancer drugs. Here, we determined whether the amino acids cystine and theanine, which provide substrates for glutathione, attenuated the AEs of S-1 adjuvant chemotherapy.

Methods Patients scheduled to receive S-1 adjuvant chemotherapy were randomized to the $\mathrm{C} / \mathrm{T}$ or the control groups. The C/T group received $700 \mathrm{mg}$ cystine and $280 \mathrm{mg}$ theanine orally 1 week before the administration of $S-1$, which then continued for 5 weeks. Each group received S-1 for 4 weeks. Blood sampling was performed and AEs were evaluated (CTCAE ver. 4.0) before and after the administration of S-1. S-1 was discontinued when AEs $\geq$ grade 2 occurred.

Results The incidences of AEs of any grade and those over grade 2 were lower in the $\mathrm{C} / \mathrm{T}$ group than in the controls. The incidence of diarrhea $(\mathrm{G} \geq 2)$ was significantly less $(p<0.05)$ in the $\mathrm{C} / \mathrm{T}$ group $(3.1 \%)$ than in the controls $(25.8 \%)$. The duration and completion rate of the S-1 adjuvant chemotherapy were significantly longer $(p<0.01)$ and
\end{abstract}

This study was presented as an Excellent Presentation at the 52nd Japanese Society of Clinical Oncology (JSCO) 2014.

Takashi Tsuchiya

tsuchiya@openhp.or.jp

1 Department of Surgery, Sendai City Medical Center, 5-22-1 Tsurugaya, Miyagino-ku, Sendai, Miyagi 983-0824, Japan

2 Department of Pharmacy, Sendai City Medical Center, Sendai, Japan

3 Institute for Innovation, Ajinomoto Co., Inc., Kanagawa, Japan

4 Wellness Business Division, Ajinomoto Co., Inc., Tokyo, Japan higher $(p<0.01)$, respectively, in the $\mathrm{C} / \mathrm{T}$ group (complete ratio: $75.0 \%$, duration: $24.8 \pm 5.8$ days) than in the controls (complete ratio: $35.5 \%$, duration: $20.0 \pm 7.7$ days). Conclusions The oral administration of cystine and theanine attenuated the AEs of S-1 adjuvant chemotherapy and increased the S-1 completion rate, suggesting that cystine and theanine is a useful supportive care for chemotherapy.

Keywords Adverse events · Chemotherapy - Cystine/ theanine $\cdot \mathrm{S}-1 \cdot$ Supportive care

\section{Introduction}

Adherence to the dosing schedule is important for the effectiveness of anticancer chemotherapy and affects therapeutic outcomes [1]. To improve adherence, measures that reduce adverse events (AEs) have been considered in the area of dosage form design, and the administration method has been modified. Drugs that suppress various symptoms have also been developed and used as supportive therapies to prevent AEs. Two examples of supportive therapies include antiemetics, which mitigate nausea, and granulocyte colony-stimulating factor (G-CSF), which treats neutropenia [2-4]. However, AEs are still difficult to control, and further development of supportive therapies is needed.

Cystine and theanine is a supplement that contains $700 \mathrm{mg}$ cystine and $280 \mathrm{mg}$ theanine; it is available in Japan and the United States. Cystine consists of two molecules of cysteine, which is a sulfur-containing amino acid, that are connected by a disulfide bond, and it is reduced and converted to cysteine in the cell. Theanine breaks down into glutamic acid and ethylamine after it is absorbed. In the cell, cysteine and glutamic acid are synthesized with glycine to form the tripeptide glutathione (GSH) [5]. GSH is 
reportedly the most potent antioxidant in the body, and its levels have been shown to decrease after exercise and surgery $[6,7]$. The need for GSH is thought to increase under these conditions. We previously described that the intake of cystine and theanine for 10 days during the perioperative period led to the early resolution of high postoperative levels of interleukin (IL)-6 and C-reactive protein (CRP) and early recovery from changes in neutrophil and lymphocyte counts [8]. Cystine and theanine has also been shown to produce similar effects in mouse digestive tract surgery models and to prevent decreases in intestinal GSH; these effects were considered to be partly explained by the supply of GSH [9].

Justino et al. showed that the GSH concentrations in the epithelial cells of the gastrointestinal mucosa in mice decreased after the administration of 5-FU; they also found that administering the intestinal bacterial species Saccharomyces boulardii prevented the decrease in GSH and alleviated diarrhea, an AE associated with the administration of 5-FU [10].

Preliminary studies using cystine and theanine have shown that this treatment reduced the severity of stomatitis caused by various chemotherapies [11], suggesting that cystine and theanine is a promising supportive therapy. Therefore, we performed a prospective randomized trial in patients undergoing surgery for either colon cancer or gastric cancer with postoperative S-1 adjuvant chemotherapy to determine the preventive effects of cystine and theanine against AEs caused by chemotherapy and to evaluate the usefulness of cystine and theanine as a supportive therapy.

\section{Patients and methods}

\section{Patients}

This study was approved by the Institutional Review Board of Sendai City Medical Center (approval number: 20120010), and consent was obtained from each patient after the study was sufficiently explained. The study was performed in accordance with the Declaration of Helsinki. The subjects comprised patients who underwent R0 surgery for either colon or gastric cancer at the surgery department of the Sendai City Medical Center and who were expected to receive postoperative S-1 adjuvant chemotherapy for 4 weeks with a 2-week drug-free interval. Patients were enrolled in the study if they were in PS0 or PS1, were 20 years of age or above, submitted written consent, and fulfilled the following criteria on their pre-registration laboratory tests: white blood cell (WBC) count $>3,000 / \mathrm{mm}^{3}$, neutrophil count $>1,500 / \mathrm{mm}^{3}$, platelet count $>100,000 / \mathrm{mm}^{3}$, hemoglobin level $>9.0 \mathrm{~g} / \mathrm{dl}$, total bilirubin level $<2.0 \mathrm{mg} / \mathrm{dl}$, aspartate aminotransferase (AST) level $<100 \mathrm{IU}$, alanine aminotransferase (ALT) level <100 IU, and estimated glomerular

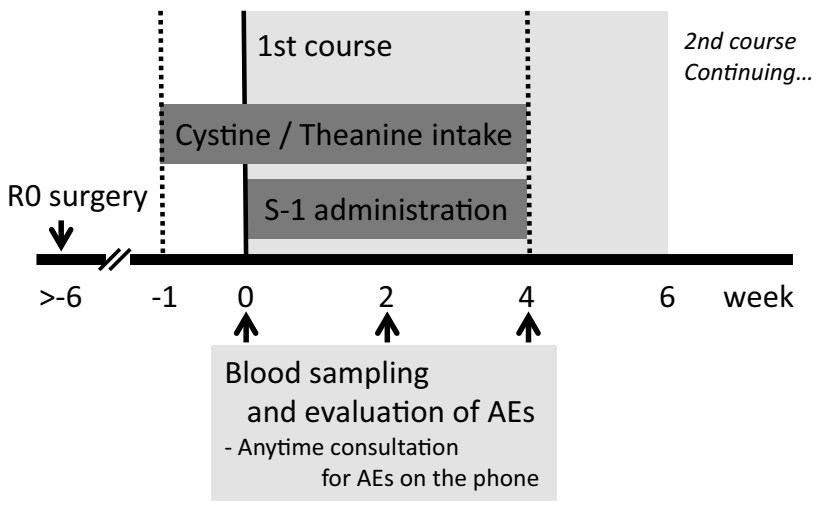

Fig. 1 Administration schedules of S-1 and cystine and theanine after R0 surgery

filtration rate $(\mathrm{eGFR})>60 \mathrm{ml} / \mathrm{min}$. The patient registration period lasted from July 2012 to June 2014, and the intended number of enrolled subjects was 70 .

\section{Study design and data collection}

The study design was a prospective randomized trial, and the subjects were allocated using the envelope method. The administration of S-1 (Taiho Pharmaceutical, Tokyo, Japan) was scheduled to be initiated within 6 weeks after surgery. The subjects in the $\mathrm{C} / \mathrm{T}$ group were orally administered an amino acid supplement, which contained $700 \mathrm{mg}$ cystine and $280 \mathrm{mg}$ theanine (total weight, $1.7 \mathrm{~g}$; Ajinomoto, Tokyo, Japan), once a day starting 1 week before and ending at the same time as the administration of S-1 (a total of 35 days) (Fig. 1). The control group received S-1 without cystine and theanine. The subjects in both groups were examined at the outpatient clinic immediately before starting S-1 chemotherapy. They underwent blood sampling, and it was confirmed that they fulfilled the inclusion criteria. The subjects visited the hospital 14 days after starting S-1 chemotherapy and at the end of the first treatment course (28 days after starting S-1 chemotherapy); during the visits, they underwent blood sampling and answered questions about AEs. The subjects were observed until the end of the first treatment course. A physician in charge of the outpatient clinic graded the AEs according to the Common Terminology Criteria for Adverse Events (CTCAE) version 4.0. If AEs that were of a grade 2 severity or more severe occurred during the chemotherapy, the administration of S-1 was suspended or discontinued, and the period in which S-1 was administered at the prescribed dose (i.e., not including the period when the dose was reduced) was recorded. Consultations regarding AEs were given by telephone and during hospital visits, and the administration of $\mathrm{S}-1$ was immediately discontinued if the $\mathrm{AE}$ was judged to be of a grade 2 severity or more severe. The evaluation 
Fig. 2 Thirty-five subjects each were randomly allocated to the control and $\mathrm{C} / \mathrm{T}$ groups. After exclusion of 4 control group subjects and $3 \mathrm{C} / \mathrm{T}$ group subjects, the data from 31 and 32 subjects in the respective groups were analyzed

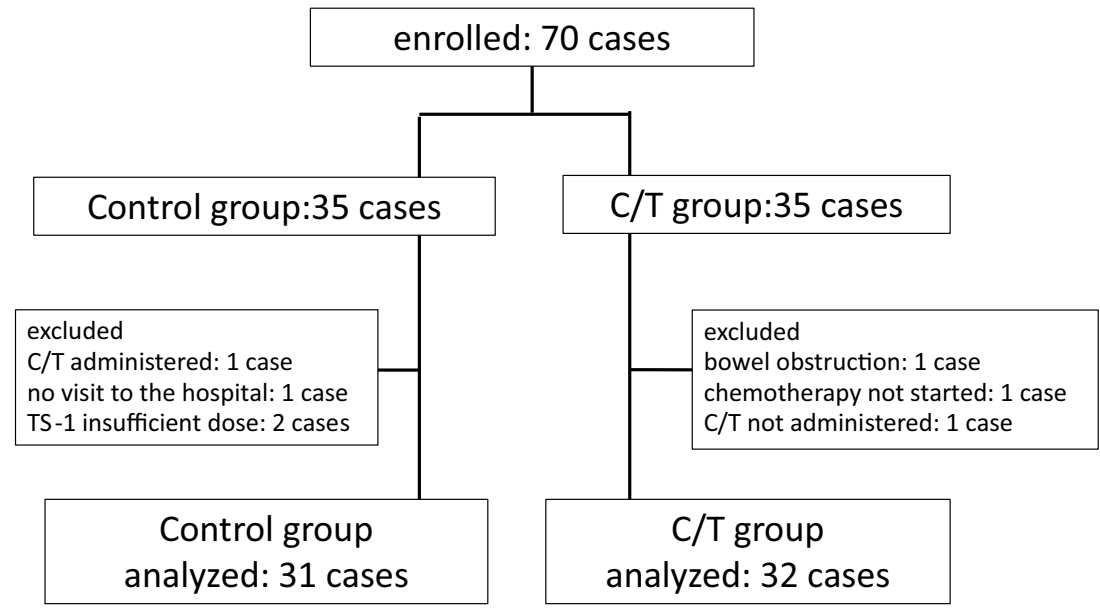

$\mathrm{C} / \mathrm{T}$ : cystine and theanine items included the incidence of AEs, which was determined through blood tests and medical interviews, and the completion rate of the first course of chemotherapy at the prescribed dose.

\section{Statistical analyses}

The hypothesis was that the completion rate of the first course of chemotherapy would be increased from $45 \%$ (less than half) to $80 \%$ by administration of cystine and theanine. It was calculated that 66 samples would be required. Expecting the loss of several samples, 70 samples were included in this study.

All data were expressed as a percentage or the mean \pm standard deviation (SD). The incidence of AEs and completion rate of chemotherapy were evaluated using Fisher's exact test. The number of days that the prescribed dose of S-1 was administered in each group was compared using the $t$ test. All statistical procedures were performed at a significance level of $p<0.05$ using the Prism software package (GraphPad Software, La Jolla, CA, USA).

\section{Results}

Of the 70 subjects who participated, 35 subjects were allocated to each group. Four subjects in the control group were excluded ( 1 had difficulty visiting the hospital because of low back pain, 2 were underdosed with $S-1$, and 1 was administered cystine and theanine), and 3 in the $\mathrm{C} / \mathrm{T}$ group were excluded ( 1 developed ileus, 1 could not be administered S-1, and 1 was not administered cystine and theanine). Thus, 31 subjects in the control group and 32 subjects in the $\mathrm{C} / \mathrm{T}$ group were evaluated (Fig. 2).
Table 1 Characteristics of the subjects in the control and C/T groups

\begin{tabular}{llll}
\hline & Control & $\mathrm{C} / \mathrm{T}$ & $p$ value \\
\hline Age (years) & $63.5 \pm 8.9$ & $63.2 \pm 8.5$ & 0.917 \\
Sex, male:female (cases) & $17: 14$ & $21: 11$ & 0.556 \\
Colon cancer (cases) & 24 & 22 & 0.517 \\
Gastric cancer (cases) & 7 & 9 & \\
Gastric/colon cancer (cases) & 0 & 1 & \\
Total (cases) & 31 & 32 & \\
\hline
\end{tabular}

Age was expressed as mean $\pm \mathrm{SD}$ and compared using the $t$ test. Numbers of subjects were compared using percentage. $p$ values were calculated using Fisher's exact test

$C / T$ cystine and theanine

The subjects in the control and $\mathrm{C} / \mathrm{T}$ groups had the following characteristics: their ages were $63.5 \pm 8.9$ and $63.2 \pm 8.5$ years, their male:female ratios were 17:14 and $21: 11$, and their diagnoses were colon cancer $(n=24$ and $n=22)$ and gastric cancer ( $n=7$ and $n=9)$, respectively; 1 patient in the $\mathrm{C} / \mathrm{T}$ group had gastric cancer and colon cancer (Table 1).

Operative procedures in each group are shown in Table 2. Open or laparoscopic procedure was not distinguished.

The following incidences for AEs (any grades) were observed in the control and $\mathrm{C} / \mathrm{T}$ groups, respectively: $16.1 \%$ and $9.4 \%$ for neutropenia, $29.0 \%$ and $18.8 \%$ for stomatitis, $38.7 \%$ and $18.8 \%$ for appetite loss, $16.1 \%$ and $18.8 \%$ for nausea, $41.9 \%$ and $9.4 \%$ for diarrhea, $22.6 \%$ and $9.4 \%$ for fatigue, $32.3 \%$ and $25.0 \%$ for pigmentation, $6.5 \%$ and $0 \%$ for exanthema, $9.7 \%$ and $0 \%$ for fever (not accompanied by neutropenia), $9.7 \%$ and $0 \%$ for abdominal pain, and $3.2 \%$ and $0 \%$ for vertigo. The incidences for 
Table 2 Operative procedures in the control and $\mathrm{C} / \mathrm{T}$ groups

\begin{tabular}{lllll}
\hline & & Control (cases) & C/T (cases) & Total (cases) \\
\hline \multirow{2}{*}{ Colon cancer } & Rt. colectomy & 5 & 8 & 13 \\
& Sigmoid colectomy & 8 & 5 & 13 \\
& Resection of rectum & 6 & 6 & 12 \\
& Miles' operation & 5 & 2 & 7 \\
Gastric cancer & Partial resection & 0 & 1 & 1 \\
\multirow{3}{*}{ Gastric/colon cancer } & Distal gastrectomy & 5 & 3 & 8 \\
Total (cases) & Total gastrectomy & 2 & 6 & 8 \\
\hline
\end{tabular}

$C / T$ cystine and theanine

Table 3 Incidence of adverse events (AEs) during the first course (28 days) of S-1 therapy

\begin{tabular}{|c|c|c|c|c|c|c|}
\hline \multirow[t]{2}{*}{ Group } & \multicolumn{2}{|l|}{ Colon cancer } & \multicolumn{2}{|l|}{ Gastric cancer } & \multicolumn{2}{|l|}{ Total } \\
\hline & Control $(n=24)$ & $\mathrm{C} / \mathrm{T}(n=22)$ & Control $(n=7)$ & $\mathrm{C} / \mathrm{T}(n=9)$ & Control $(n=31)$ & $\mathrm{C} / \mathrm{T}(n=32)$ \\
\hline Adverse event (AE) (grade) & Any $(G \geq 2)$ & Any $(G \geq 2)$ & Any $(G \geq 2)$ & Any $(G \geq 2)$ & Any $(\mathrm{G} \geq 2)$ & Any $(G \geq 2)$ \\
\hline Neutropenia \% & $16.7(16.7)$ & $0(0)$ & $14.2(14.2)$ & $33.3(33.3)$ & $16.1(16.1)$ & $9.4(9.4)$ \\
\hline Stomatitis & $29.2(8.3)$ & $13.6(0)$ & $28.6(28.6)$ & $22.0(0)$ & $29.0(12.9)$ & $18.8(3.1)$ \\
\hline Appetite loss & $41.7(20.8)$ & $9.1 *(0)$ & $28.6(14.2)$ & $44.4(22.2)$ & $38.7(19.4)$ & $18.8(6.3)$ \\
\hline Nausea & $16.7(12.5)$ & $18.2(4.5)$ & $14.2(0)$ & $22.2(0)$ & $16.1(9.7)$ & $18.8(3.1)$ \\
\hline Diarrhea & $41.7(25.0)$ & $4.5 * *(4.5)$ & $42.9(28.6)$ & $11.1(0)$ & $41.9(25.8)$ & $9.4 * *\left(3.1^{*}\right)$ \\
\hline Fatigue & $16.7(12.5)$ & $9.1(0)$ & $42.9(14.2)$ & $11.1(0)$ & $22.6(12.9)$ & $9.4(0)$ \\
\hline Pigmentation & $25.0(0)$ & $22.7(0)$ & $57.1(0)$ & $22.2(0)$ & $32.3(0)$ & $25.0(0)$ \\
\hline Exantheme & $8.3(4.2)$ & $0(0)$ & $0(0)$ & $0(0)$ & $6.5(3.2)$ & $0(0)$ \\
\hline Fever & $4.2(4.2)$ & $0(0)$ & $28.6(28.6)$ & $0(0)$ & $9.7(9.7)$ & $0(0)$ \\
\hline Abdominal pain & $8.3(8.3)$ & $0(0)$ & $14.3(14.3)$ & $0(0)$ & $9.7(9.7)$ & $0(0)$ \\
\hline Vertigo & $4.2(4.2)$ & $0(0)$ & $14.3(14.3)$ & $0(0)$ & $3.2(3.2)$ & $0(0)$ \\
\hline
\end{tabular}

AEs were evaluated using the CTCAE (ver. 4.0)

$C / T$ cystine and theanine

$* p<0.05 ; * * p<0.01$ vs. control

all AEs, except nausea, were lower in the $\mathrm{C} / \mathrm{T}$ group than in the control group, and a significant difference $(p<0.01)$ was observed in the incidence of diarrhea (Table 3 ). The following incidences for AEs that were of a grade 2 or more severity (at which point $\mathrm{S}-1$ administration was suspended or discontinued) were observed in the control and the $\mathrm{C} / \mathrm{T}$ groups, respectively: $16.1 \%$ and $9.4 \%$ for neutropenia, $12.9 \%$ and $3.1 \%$ for stomatitis, $19.4 \%$ and $6.3 \%$ for appetite loss, $9.7 \%$ and $3.1 \%$ for nausea, $25.8 \%$ and $3.1 \%$ for diarrhea, $12.9 \%$ and $0 \%$ for fatigue, and $0 \%$ and $0 \%$ for pigmentation. The incidences for all these AEs were lower in the CT group than in the control group, and a significant difference $(p<0.05)$ was observed in the incidence of diarrhea. Exanthema (3.2\%), fever $(9.7 \%)$, abdominal pain $(9.7 \%)$, and vertigo $(3.2 \%)$ were noted in only the control group (Table 3 ). With regard to operative procedure, incidences of all AEs, except neutropenia and appetite loss in gastric cancer patients, were lower in the
$\mathrm{C} / \mathrm{T}$ group than in the control group in both colon cancer and gastric cancer patients. The incidence of appetite loss and diarrhea of any grade was significantly lower $(p<0.05$ and $p<0.01$, respectively) in the $\mathrm{C} / \mathrm{T}$ group than in the control group in colon cancer patients.

The percent of subjects who were able to complete the first course of chemotherapy at the prescribed dose was significantly higher $(p<0.01)$ in the $\mathrm{C} / \mathrm{T}$ group $(75.0 \%)$ than in the the control group (35.5\%) (Table 4). According to sub-analyses, completion rate was significantly higher $(p<0.01)$ in $\mathrm{C} / \mathrm{T}$ group $(90.9 \%)$ than control group $(41.7 \%)$ in colon cancer patients, and higher, but not significant, in C/T group (44.4\%) than control group (14.3\%) in gastric cancer patients (Table 4).

The duration of the administration period in which S-1 could be administered at the prescribed dose without suspension or discontinuation during the first treatment course (scheduled to be 28 days) was significantly longer $(p<0.01)$ in the $\mathrm{C} / \mathrm{T}$ group 
Table 4 Completion rate and the duration of the administration period in which S-1 should be administered at the prescribed dose without suspension or discontinuation during first treatment course (28 days)

\begin{tabular}{|c|c|c|c|c|c|c|}
\hline \multirow[t]{2}{*}{ Group } & \multicolumn{2}{|c|}{ Colon cancer } & \multicolumn{2}{|c|}{ Gastric cancer } & \multicolumn{2}{|l|}{ Total } \\
\hline & Control & $\mathrm{C} / \mathrm{T}$ & Control & $\mathrm{C} / \mathrm{T}$ & Control & $\mathrm{C} / \mathrm{T}$ \\
\hline Completion rate of first course of treatment (cases) & $10 / 24$ & $20 / 22$ & $1 / 7$ & $4 / 9$ & $11 / 31$ & $24 / 32$ \\
\hline Percent $(\%)$ & 41.7 & $90.9 * *$ & 14.3 & 44.4 & 35.5 & $75.0 * *$ \\
\hline Duration (days) & $21.0 \pm 7.4$ & $26.8 \pm 3.8 * *$ & $16.3 \pm 8.0$ & $21.1 \pm 6.8$ & $20.0 \pm 7.7$ & $24.8 \pm 5.8 * *$ \\
\hline
\end{tabular}

Duration was expressed as mean $\pm \mathrm{SD}$ and compared using the $t$ test

$C / T$ cystine and theanine

$* * p<0.01$ vs. control

(24.8 \pm 5.8 days) than in the control group (20.0 \pm 7.7 days) According to sub-analyses, the duration was significantly longer ( $p<0.01)$ in the $\mathrm{C} / \mathrm{T}$ group $(26.8 \pm 3.8$ days) than in the control group (21.0 \pm 7.4 days) in colon cancer patients, and longer, but not significant, in the $\mathrm{C} / \mathrm{T}$ group ( $21.1 \pm 6.8$ days) than in the control group (16.3 \pm 8.0 days) in gastric cancer patients (Table 4$)$.

\section{Discussion}

The ACTS-GC study reported that the use of S-1 adjuvant chemotherapy for treating stage II/III gastric cancer increased the 5-year survival rate after surgery alone from $61.7 \%$ to $71.7 \%$ and improved the hazard risk by $32 \%$ [12]. A study in Japan that assessed the regimen of orally administering uracil, tegafur, and leucovorin (UFT/LV) as an adjuvant chemotherapy after colon cancer surgery found that it was not inferior to intravenous 5-FU and levofolinate (5-Fu/LV) therapy [13]. UFT/LV is recommended in the guidelines; however, the ACTS-CC study demonstrated that S-1 is not inferior to UFT/LV [14]. The results of this study demonstrated that S-1 adjuvant chemotherapy was effective following surgery for gastric or colon cancer.

AEs associated with the administration of S-1 have been shown to affect the duration of the administration period; S-1 administered was continued for 12 months with suspensions and dose reductions in $65.8 \%$ (340/517) of the patients after gastrectomy in the ACTS-GC study [12] and for 6 months in $76.5 \%$ of the patients after large bowel resection in the ACTSCC study [14]. As dose reductions were necessary because of the occurrence of AEs in $46.5 \%$ (158 patients) of the 340 patients who completed the therapy in the ACTS-GC study, the percent of patients who completed the therapy without dose reductions was $35.2 \%$ (182/517 patients) [12]. In a study by Maekawa et al., S-1 was administered for 12 months in $65 \%$ of the 40 patients after gastrectomy, and only $23 \%$ of the patients did not require a change in the administration schedule or a reduction in dose [15]. According to sub-analyses of the ACTSGC study results, the outcomes were more favorable among the patients who could continue receiving treatment for 12 months and the patients who received $70 \%$ or more of the planned dose [16]. Therefore, how well AEs can be controlled and how much of the scheduled dose can be administered within the scheduled treatment period are considered to markedly affect the therapeutic outcomes of S-1 adjuvant chemotherapy.

In the present clinical trial, cystine and theanine was shown to alleviate the AEs associated with the use of S-1. Moreover, during the first course of S-1 therapy, cystine and theanine significantly increased the number of days on which S-1 could be administered and significantly improved the completion rate of the therapy at the prescribed dose from $35.5 \%$ to $75.0 \%$. Especially, the completion rate of colon cancer patients improved from $41.7 \%$ to $90.9 \%$. The findings also suggest that cystine and theanine alleviates all AEs, in contrast to drugs such as antiemetics, that target particular symptoms. No study has yet demonstrated improvements in the completion rate of anticancer regimens through the use of particular supportive therapies. With respect to the specific symptoms, significant suppression was observed only for diarrhea; however, the effects on the other symptoms may also be significant in large-scale studies. The AEs associated with S-1 most frequently occur during the first few treatment courses. If cystine and theanine can improve the completion rate of the first treatment course, its suppressive effects on AEs may be sustained in subsequent courses in patients who continue to take it. In a previous study, we were able to administer the $\mathrm{S}-1$ regimen as scheduled without AEs by the continuous administration of cystine and theanine in a small number of patients.

With respect to the dose, the final dosage form of the cystine and theanine amino acid supplement, which contained $700 \mathrm{mg}$ cystine and $280 \mathrm{mg}$ theanine, weighed $1.7 \mathrm{~g}$, and it was readily ingested even by patients with gastrointestinal symptoms, which is a major advantage. The findings of all the clinical trials to date are based on the combination of $700 \mathrm{mg}$ cystine and $280 \mathrm{mg}$ theanine; future studies should evaluate the optimal dose. In an experiment using mice, its effects were not intensified at higher doses, suggesting that there is an optimal dose $[9,17]$.

Although the action mechanism of cystine and theanine has not yet been elucidated in detail, it likely involves an increase 
in the cellular concentration of GSH in the organs that are involved in the AEs which occur. Cystine and theanine provides cysteine and glutamic acid to cells, and in combination with glycine, they increase intracellular GSH concentrations. The use of an anticancer agent is expected to increase oxidative stress in cells and to reduce the concentration of GSH, which is a potent antioxidant. Because the administration of cystine and theanine for 5 days before laparotomy suppressed decreases in GSH in the small bowel mucosa and Peyer's patches of mice [9], this may be the mechanism responsible for alleviation of the AEs caused by anticancer chemotherapy. A previous study involving 14 patients who had colorectal cancer and underwent adjuvant chemotherapy with 5-FU and oxaliplatin reported that the incidence of sensory neuropathy was significantly lower in 5 patients who were orally administered $\mathrm{N}$-acetylcysteine, a GSH precursor, at $1200 \mathrm{mg}$ than in the 9 patients who were not administered the supplement [18]. Another study found that among 52 patients who had colorectal cancer and underwent oxaliplatin-based chemotherapy, a significantly stronger neuroprotective effect was observed in the group that received intravenous GSH at $1500 \mathrm{mg} / \mathrm{m}^{2}$ before the administration of oxaliplatin [19]. The regimens evaluated in these clinical studies also aimed to alleviate the AEs caused by chemotherapy by increasing the GSH concentration in normal cells.

In conclusion, the intake of the amino acids cystine and theanine at 700 and $280 \mathrm{mg}$, respectively, alleviated the AEs caused by the anticancer drug S-1, reduced the frequency of therapy suspension or discontinuation caused by AEs, and improved the completion rate of the first course of therapy.

Acknowledgments The authors thank Makiko Kashima, B.Sc., Katsushi Takahashi, B.Sc., and Atsushi Kudoh, Ph.D. (Department of Pharmacy, Sendai City Medical Center, Sendai, Japan) for their support in the AE consultations that were conducted by telephone.

Funding This work was supported by Ajinomoto Co., Inc.

\section{Compliance with ethical standards}

Conflict of interest No author has any conflict of interest.

Open Access This article is distributed under the terms of the Creative Commons Attribution 4.0 International License (http://creativecommons.org/licenses/by/4.0/), which permits unrestricted use, distribution, and reproduction in any medium, provided you give appropriate credit to the original author(s) and the source, provide a link to the Creative Commons license, and indicate if changes were made.

\section{References}

1. Bonadonna G, Valagussa P (1981) Dose-response effect of adjuvant chemotherapy in breast cancer. N Engl J Med 304(1):10-15. doi:10.1056/NEJM198101013040103

2. Basch E, PrestrudAA, Hesketh PJ et al (2011)Antiemetics: American Society of Clinical Oncology clinical practice guideline update. J Clin Oncol 29(31):4189-4198. doi:10.1200/JCO.2010.34.4614
3. Roila F, Herrstedt J, Aapro M et al (2010) Guideline update for MASCC and ESMO in the prevention of chemotherapy- and radiotherapy-induced nausea and vomiting: results of the Perugia consensus conference. Ann Oncol 21(suppl 5):v232-v243. doi:10.1093/annonc/mdq194

4. Smith TJ, Khatcheressian J, Lyman GH et al (2006) 2006 update of recommendations for the use of white blood cell growth factors: an evidence-based clinical practice guideline. J Clin Oncol 24(19):3187-3205. doi:10.1200/JCO.2006.06.4451

5. Kurihara S, Shibakusa T, Tanaka KA (2013) Cystine and theanine: amino acids as oral immunomodulative nutrients. SpringerPlus 2:635. doi:10.1186/2193-1801-2-635

6. Luo JL, Hammarqvist F, Andersson K et al (1996) Skeletal muscle glutathione after surgical trauma. Ann Surg 223(4):420-427

7. Margonis K, Fatouros IG, Jamurtas AZ et al (2007) Oxidative stress biomarkers responses to physical overtraining: implications for diagnosis. Free Radic Biol Med 43(6):901-910. doi:10.1016/j.freeradbiomed.2007.05.022

8. Miyachi T, Tsuchiya T, Oyama A et al (2013) Perioperative oral administration of cystine and theanine enhances recovery after distal gastrectomy: a prospective randomized trial. JPEN J Parenter Enteral Nutr 37(3):384-391. doi:10.1177/0148607112458798

9. Shibakusa T, Mikami T, Kurihara S et al (2012) Enhancement of postoperative recovery by preoperative oral co-administration of the amino acids, cystine and theanine, in a mouse surgical model. Clin Nutr 31(4):555-561. doi:10.1016/j.clnu.2012.02.001

10. Justino PF, Melo LF, Nogueira AF et al (2014) Treatment with Saccharomyces boulardii reduces the inflammation and dysfunction of the gastrointestinal tract in 5-fluorouracil-induced intestinal mucositis in mice. Br J Nutr 111(9):1611-1621. doi:10.1017/ S0007114513004248

11. Tsuchiya T, Honda H, Oikawa M et al (2014) Effect of oral administration of amino acids cystine and theanine on chemotherapy induced mucositis. J Jpn Soc Clin Oncol 49(3):2324

12. Sakuramoto S, Sasako M, Yamaguchi T et al (2007) Adjuvant chemotherapy for gastric cancer with S-1, an oral fluoropyrimidine. N Engl J Med 357(18):1810-1820. doi:10.1056/NEJMoa072252

13. Shimada Y, Hamaguchi T, Mizusawa J et al (2014) Randomised phase III trial of adjuvant chemotherapy with oral uracil and tegafur plus leucovorin versus intravenous fluorouracil and levofolinate in patients with stage III colorectal cancer who have undergone Japanese D2/D3 lymph node dissection: final results of JCOG0205. Eur J Cancer 50(13):2231-2240. doi:10.1016/j.ejca.2014.05.025

14. Yoshida M, Ishiguro M, Ikejiri K et al (2014) S-1 as adjuvant chemotherapy for stage III colon cancer: a randomized phase III study (ACTS-CC trial). Ann Oncol 25(9):1743-1749. doi:10.1093/annonc/mdu232

15. Maekawa T, Mikami K, Kawahara K et al (2008) Current state of adjuvant chemotherapy using S-1 for curative resected gastric cancer patients at two referable university hospitals in Fukuoka. Med Bull Fukuoka Univ 35(3):127-130

16. Sakuramoto S, Kikuchi S, Watanabe M (2009) Effects of S-1 (oral fluorinated pyrimidine) on gastric cancer (in Japanese). Med Frontline 64(5):1075-1080

17. Tanaka KA, Kurihara S, Shibakusa T et al (2014) Cystine improves survival rates in a LPS-induced sepsis mouse model. Clin Nutr. doi:10.1016/j.clnu.2014.11.014

18. Lin PC, Lee MY, Wang WS et al (2006) N-Acetylcysteine has neuroprotective effects against oxaliplatin-based adjuvant chemotherapy in colon cancer patients: preliminary data. Support Care Cancer 14(5):484-487. doi:10.1007/s00520-006-0018-9

19. Cascinu S, Catalano V, Cordella L et al (2002) Neuroprotective effect of reduced glutathione on oxaliplatin-based chemotherapy in advanced colorectal cancer: a randomized, double-blind, placebo-controlled trial. J Clin Oncol 20(16):3478-3483 